EESTI NSV TEADUSTE AKADEEMIA TOIMETISED. 28. KOIDE

GEOLOOGIA. 1979, NR. 4

ИЗВЕСТИЯ АКАДЕМИИ НАУК ЭСТОНСКОЯ ССР. ТОМ 28 ГЕОЛОГИЯ. 1979, № 4

УдК $556.382: 556.072(474.2)$

\author{
Алиде ВИИГАНД, Л. САВИЦКИИ, Р. МОКРИК
}

\title{
ОСОБЕННОСТИ ФОРМИРОВАНИЯ ЭКСПЛУАТАЦИОННЫХ РЕСУРСОВ ПОДЗЕМНЫХ ВОД ЭСТОНСКОЙ ССР
}

Подземные воды в Эстонской ССР являются одним из основных источников водоснабжения городов, промышленных и сельскохозяйственных объектов. Поэтому исследование закономерностей формирования и распределения эксплуатационных ресурсов подземных вод имеет весьма важное значение при разработке мероприятий рациснального управления режимом как подземных, так и поверхностных вод.

Впервые региональная оценка эксплуатационных ресурсов подземных вод на рассматриваемой территории была выполнена в начале 60-х годов Управлением геологии ЭССР под методическим руководством ВСЕГИНГЕО. Однако, несмотря на большую научную и практическую ценность выполненной работы, в ней имели место некоторые недостатки, обусловленные методикой работ и недостаточной изученностью условий формирования ресурсов подземных вод. Так, например, в расчетах не были учтены сложные процессы фильтрации, возникающие в результате взаимодействия водоносных комплексов в условиях многослойного строения водовмещающей толщи, а также взаимодействие подземных вод с поверхностными. Вследствие этого отбор потенциальных эксплуатационных ресурсов подземных вод условно заданными водозаборами не является гарантированным и реальным.

В связи с этим возникает необходимость в рассмотрении условий формирования ресурсов подземных вод с новых позиций, основываясь на перспективном плане развития народного хозяйства республики и учете конкретных водопотребителей, а также с привлечением современных методов математического моделирования. Кроме того, за последние 10-15 лет в результате гидрогеологических исследований в геологическом фонде накопился обширный материал нового качества по опыту эксплуатации и разведки подземных вод и изучению подземного стока, позволяющий в значительной мере повысить достоверность расчетов.

C постоянным развитием промышленного и сельскохозяйственного производства, ростом городов и улучшением культурно-бытовых условий населения республики из года в год увеличивается использование пресных подземных вод. Из опыта эксплуатации городских водозаборов известно, что ежегодный прирост потребления подземных вод в Эстонской ССР составляет в среднем 5-10\%. Основная нагрузка водоотбора падает на водоснабжение крупных городов - Таллина, Кохтла-Ярве, Пярну, Тарту и др. В целом водопотребление по городам и населенным пунктам Эстонской ССР составляет около $65 \%$ от общего потребления. На водоснабжение сельскохозяйственных объектов и ин- 
дивидуальных водопотребителей в сельской местности приходится $35 \%$. Средний модуль водопотребления на территории Эстонской ССР составляет около $0,1 \Omega / c е \kappa$ с $1 \kappa \mu^{2}$. Основная часть водоотбора сконцентрирована в северной части республики и имеет свои особенности формирования эксплуатационных ресурсов подземных вод.

Прогноз эксплуатационных ресурсов подземных вод осуществлялся путем математического моделирования с учетом перспективного водопотребления конкретных водопотребителей. По городам и населенным .пунктам потребность рассчитана ГПИ «Эстонпроект», для сельских районов - ЛитНИГРИ, при этом учитывались перспективы развития сельского хозяйства (Иодказис, Мокрик, 1973). Путем математического моделирования с учетом как природных условий, так и особенностей эксплуатации выяснено, что в целом по республике эксплуатационные ресурсы покрывают потребность в хозяйственно-питьевой воде до 2000 г. Обобщенный модуль эксплуатационных ресурсов равняется $0,45 \Omega / c е \kappa$ с $1 \kappa \mu^{2}$. Весьма острое положение создается в северной части республики, особенно в Таллине, Силламяэ, Нарве, где потребность в воде покрывается и за счет привлечения поверхностных источников водоснабжения.

Применение методов математического моделирования позволило в сложных гидрогеологических условиях рассматриваемого региона определить структуру формирования ресурсов подземных вод при сильно нарушенном их режиме. Основными источниками формирования эксплуатационных ресурсов являются естественные ресурсы, привлекаемые из поверхностных водоемов, и емкостные запасы (рисунок). На территории Эстонской ССР четко выделяются две гидродинамические зоны: верхняя - зона интенсивного водообмена, нижняя - затрудненного водообмена.

Швянтой ско-ст арооскольски й и силури й ско-ордовикский водоносные комплексы приурочены к верхней гидродинамической зоне, и их эксплуатационные ресурсы формируются в основном за счет естественных ресурсов, которые составляют $82-86 \%$. На долю поверхностных вод приходится $11-13 \%$ и на сработку емкостных запасов - 3-5\% (рисунок, $a, \sigma)$.

В формировании эксплуатационных ресурсов в расчетной схеме заложения водозаборов для пя ннуско-силурий ского водоносного горизонта на долю естественных ресурсов приходится $77 \%$, поверхностные источники составляют $13 \%$ и сработка емкостных запасов $10 \%$ (рисунок, в).

В ордовикско-кемб рийском водоносном горизонте, залегающем на относительно больших глубинах, в формировании эксплуатационных ресурсов основную роль играют перетекания через разделяющие слабопроницаемые слои, за счет которых формируется $84 \%$ эксплуатационных ресурсов (рисунок, г).

В кем бро-вендском водоносном комплексе основная роль в формировании эксплуатационных ресурсов принадлежит притоку со стороны моря. При эксплуатации подземных вод кембро-вендского водоносного комплекса постепенно происходит изменение их качества, вызванное продвижением фронта соленых морских вод к береговым водозаборам. Ориентировочный прогноз скорости движения контура морских вод показывает, что качество пресной воды на береговых водозаборах не изменится еще в течение 25-30 лет. Однако уже сейчас необходимо организовать тщательный контроль за изменением химического состава подземных вод, а также предусмотреть переустройство водозаборов в будущем. Особенностью формирования эксплуатацион- 
а) Шьянтойско-старооскольСКий Бодоносный комплекС

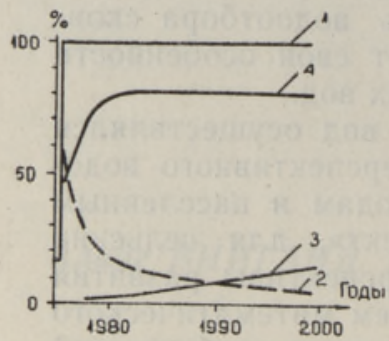

b) Пярнуско-силурийскии Водоносный комплекс

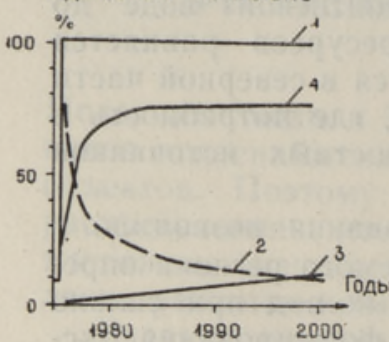

б) Силурииско- ораоБикскии Бодоносный комплекс

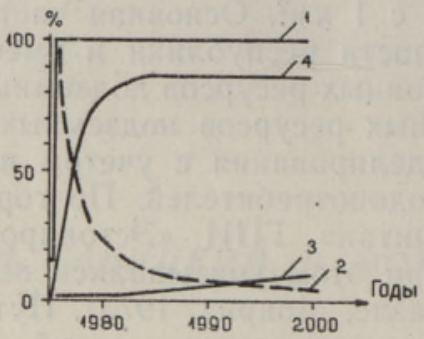

г) Ордобикско-кемориникии

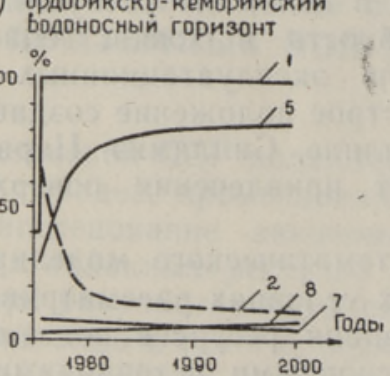

A) Кембро-Бендский Бадоносныи

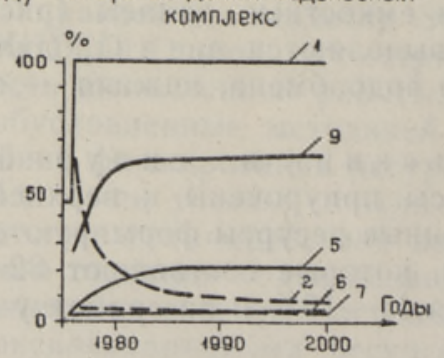

Балансовые графики эксплуатационных ресурсов подземных вод Әстонской ССР.

1 - суммарный дебит водозаборов, 2 - кривая сработки емкостных запасов, 3 - питание за счет поверхностных вод, 4 - привлекаемые естественные ресурсы, 5 площадное перетекание сверху, 6 - перетекание из погребенных долин, 7 - боковой приток, 8 - площадное перетекание снизу, 9 - естественные запасы, замещаемые морскими водами.

ных ресурсов этого комплекса является перетекание из погребенных долин в прибрежной морской полосе, которое также существенно изменяет химический состав воды и отражается на положении уровней (рисунок, $\partial$ ).

Специфику формирования эксплуатационных ресурсов подземных вод необходимо учитывать в процессе их потребления и при планировании мероприятий по охране вод от истощения и загрязнения. Так, для верхней зоны, особенно в пределах распространения трещиннокарстовых вод, при централизованных водозаборах необходимо предусматривать специальные зоны санитарной охраны, ограничивать строительство объектов, потенциально загрязняющих подземные воды. На данном этапе необходима также организация режимной сети на четвертичном, швянтойско-старооскольском и силурийско-ордовикском водоносных комплексах с целью изучения загрязнения подземных вод пестицидами, фенолами и другими сточными продуктами.

Таким образом, исследования ресурсов подземных вод могут послужить основой для разработки генеральной схемы комплексного использования их в пределах рассматриваемого региона, а также при планировании поисково-разведочных работ и технико-экономическом обосновании организации режимно-наблюдательной сети республики. 


\title{
Л ИТ Е РА Т У РА
}

Иодказис В. И., Мокрик Р. В. Методика систематизации исходной гидрогеологической информации и легенда комплекса карт для региональной оценки эксплуатационных запасов подземных вод. - В кн.: Мат. межреспубликанского семинара «Региональные вопросы оценки эксплуатационных запасов пресных подземных вод Прнбалтийского артезнанского бассейна», Вильнюс, 1973,
c. $74-90$.

Управление геологии Совета Министров ЭССР

Литовский научно-исследовательский геологоразведочный институт
Поступила в редакцию 29/III 1979

Alide VIIGAND, L. SAVITSKI, R. MOKRIK

\section{PŌHJAVEE TARBEVARUDE KUJUNEMISE ISEARRASUSED EESTI NSV-S}

\begin{abstract}
Matemaatiline modelleerimine võimaldas määrata vaadeldud ala keerulistes hüdrogeoloogilistes tingimustes põhjavee tarbevarude kujunemist tugevalt rikutud põhjavee-
režiimi puhul.

Peamisteks tarbevarude moodustajateks on pōhjavee looduslikud ressursid, pinnaveed ja staatilised varud. Intensiivse veevahetuse vöös kujunevad tarbevarud põhiliSelt looduslikest ressurssidest, pinnavesi ja staatilised varud moodustavad vaid $3-13 \%$. Ordoviitsiumi-kambriumi veehorisondi tarbevarudest moodustub $84 \%$ ülemistest põhjaveekihtidest pärinevast veest. Kambriumi-vendi põhjaveekompleksi tarbevarude moodustumises on pōhiline osa mere poolt tuleval juurdevoolul. Intensiivse tarbimise korral mage põhjavesi asendub järk-järgult soolase mereveega. Rannikualal vôtab tarbevarude moodustamisest osa mattunud orgudest tulev vesi, mistôttu muutub oluliselt
põhjavee keemiline koostis.
\end{abstract}

\section{Alide VIIGAND, L. SAVITSKI, R. MOKRIK}

\section{PECULIARITIES IN THE FORMATION OF EXPLOITABLE UNDERGROUND WATER RESOURCES IN THE ESTONIAN SSR}

Mathematical modelling enabled to determine the formation of exploitable under. ground water resources of this region, which proceeded under complicated hydrological

The principal exploitable water resources are represented underground water regime, waters, surficial waters and statical resources are represented by natural underground the exploitable water resources are mainly formed zones of an intense water exchange, ficial waters and statical stores are mainly formed by the natural water stock; sur-

In case of the Ordovician-Cambrian but $3-13 \%$ of the total resources. are formed by water coming from the water horizon, $84 \%$ of exploitable resources the region of the Cambrian-Vendian uppermost strata of underground waters. In main portion of exploitable resources is derived of underground water, however, the In case of an intense water consumption, the fresh the flow coming from the sea, replaced by salty sea-water. In the littoral the fresh underground water is gradually valleys contributes a share in the formation area, the water coming from the buried case the chemical composition of undermation of exploitable water resources, in which case the chemical composition of underground waters undergoes considerable changes. 